Original scientific paper

\title{
MRP SYSTEMS CONSIDERING FUZZY CAPACITY, LEAD TIMES AND INVENTORY AVAILABILITY
}

\author{
Cano, J. A.,"\#; Gomez-Montoya, R. A..*; Cortes, P. ${ }^{* * *} \&$ Campo, E. A.**** \\ * Universidad de Medellín, Carrera 87 \# 30 - 65, Medellín, Colombia \\ ${ }^{* *}$ Politécnico Colombiano Jaime Isaza Cadavid, Carrera 48 No. 7 - 151, Medellín, Colombia \\ **** Escuela Técnica Superior de Ingeniería, Universidad de Sevilla, Camino de los Descubrimientos s/n, \\ Sevilla 41092, Sevilla, Spain \\ ***** ESACS - Escuela Superior en Administración de Cadena de Suministro, Calle 4 \# 18-55, \\ Medellín, Colombia \\ E-mail: jacano@udem.edu.co $\left({ }^{\#}\right.$ Corresponding author $)$
}

\begin{abstract}
This article aims to propose a fuzzy model for closed-loop material requirement planning (MRP) systems considering uncertain parameters like production capacity, on-hand inventory and lead times. For this, a deterministic closed-loop MRP model is proposed, and then fuzzy coefficients in the constraints of the model are used to establish the fuzzy MRP model, which depends on the degrees of satisfaction $(\lambda)$ of the decision-maker. Data from a production plan of a company dedicated to the manufacture of electrical transformers are employed to verify the proposed fuzzy MRP model, minimizing inventory holding costs, production setup costs, and extra capacity costs. The results show the fuzzy model performs better than the deterministic model, especially for low $\lambda$ values, providing better performance in terms of the total cost, total inventory, service level, and computational efficiency. (Received in September 2020, accepted in November 2020. This paper was with the authors 2 weeks for 1 revision.)
\end{abstract}

Key Words: MRP, Fuzzy Logic, Lead Time, Inventory, Production Capacity

\section{INTRODUCTION}

Material Requirements Planning (MRP) represents an approach for converting the gross requirements of finished product given by the Master Production Schedule (MPS) into a replenishment schedule for raw materials and component parts described in a bill of materials (BOM) that seeks to comply with the due dates [1]. For this, MRP considers external and internal demand requirements, lead times, on-hand inventory, resource capacity constraints, among other elements [2]. Therefore, MRP provides production control through the dimensions of quantities and timing, balancing the trade-off between efficiency and cost [3] since the inventory represents a serious money investment for any company, and in turn inventories enhance operational flexibility and ensure a constant flow of materials in the production chain [4].

MRP has prevailed over time as the most widely used production planning system, especially in discrete parts manufacturing, and is combined with other manufacturing techniques to improve its performance and scope [5]. MRP application sectors include the machine industry [6], the management of crude oil inventory [7], the automobile industry [8], the garment industry [9], among others. However, not every MRP system offers satisfactory operation [10], due to the fact that, since its origins, shortcomings have been identified in capacity management [2], lot sizes and fixed delivery times [11], integration with shop floor extensions [2] and the uncertainty management that affects the performance of MRP production plans $[5,12]$. In order to mitigate risks, some parameters of the MRP cannot be assumed as deterministic in uncertain environments, such as those faced by supply chains [13]. In an MRP system, some uncertainty sources can be mentioned like customer demand fluctuations [14], the lead time length, supply reliability, production capacity, inventory levels [12], product 
quality, production system failures, among others [15], and this uncertainty can be caused by randomness or lack of knowledge [16]. Therefore, considering uncertainty in MRP systems allows the creation of realistic models, which generate superior planning decisions to those of deterministic models [17].

In most cases, an MRP model operates in uncertain environments in which statistical data are not reliable or even available for parameters like demand and capacity [18] due to rapid market and technological changes in companies, making the use of probability distributions and stochastic approaches impractical [16]. Consequently, fuzzy logic allows modelling uncertainty through possibility functions [19], offering a more rational decision-making approach based on expert opinion rather than using probability distributions [20, 21]. According to [16], it is necessary to distinguish whether the uncertainty management is required due to the lack of clarity or flexibility in constraints and goals, for which fuzzy constraints are modelled, or it is required due to lack of knowledge of parameters [22], for which systemic uncertainty is modelled with fuzzy coefficients [17].

Therefore, MRP parameters are considered with uncertainty through fuzzy constraints, fuzzy coefficients [16], or flexibility in the objective functions [21]. Table I shows the main studies addressing MRP systems with fuzzy logic, identifying for each study the modelling and solution approach, as well as the parameters considered with uncertainty. It shows that the most used fuzzy parameters in MRP systems are market demand and lead times, as highlighted by [23], but in addition, it is observed that capacity data has become even more relevant than lead times in the analysed works. Likewise, the works that usually consider the largest number of parameters and fuzzy conditions in MRP systems are those of [16-18], [21], and [24]; and that the optimization of linear programming is the prevalent modelling and solution approach, followed by fuzzy inference systems (FIS).

Table I: Modelling approaches and fuzzy parameters in MRP models.

\begin{tabular}{|c|c|c|c|c|c|c|c|c|c|c|c|c|}
\hline \multirow[b]{2}{*}{ Authors } & \multirow[b]{2}{*}{$\begin{array}{l}\text { Modelling and solution } \\
\text { approach }\end{array}$} & \multicolumn{11}{|c|}{ Fuzzy parameters } \\
\hline & & 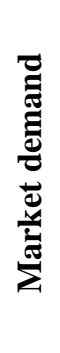 & 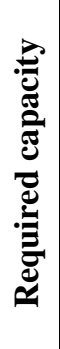 & 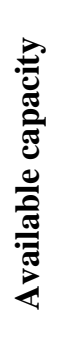 & 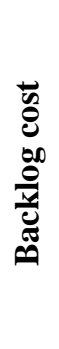 & 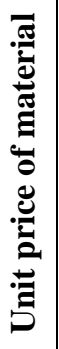 & 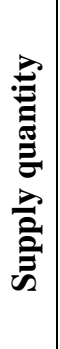 & 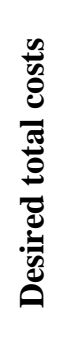 & 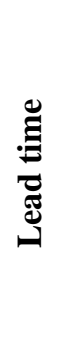 & 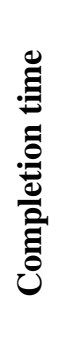 & 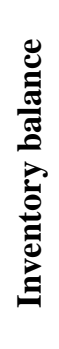 & 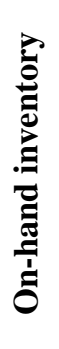 \\
\hline [21] & Optimization, linear programming & $\checkmark$ & & $\checkmark$ & & & & $\checkmark$ & & & & \\
\hline [25] & Fuzzy Inference System & & & & & & & & $\checkmark$ & & & \\
\hline$[16,17]$ & Optimization, linear programming & $\checkmark$ & $\checkmark$ & $\checkmark$ & $\checkmark$ & & & & & & & \\
\hline [24] & Optimization, linear programming & $\checkmark$ & & & & & & $\checkmark$ & & $\checkmark$ & & \\
\hline [26] & Optimization, linear programming & $\checkmark$ & & & & $\checkmark$ & & & & & & \\
\hline [27] & Optimization, linear programming & & & $\checkmark$ & & & & & & & $\checkmark$ & \\
\hline [28] & Graph approach & $\checkmark$ & & & & & & & $\checkmark$ & & & \\
\hline [18] & Optimization, linear programming & $\checkmark$ & $\checkmark$ & $\checkmark$ & & & & & & & & \\
\hline$[5,29,30]$ & Optimization, linear programming & & & & & & & & $\checkmark$ & & & \\
\hline Our proposal & Optimization, linear programming & & & $\checkmark$ & & & & & $\checkmark$ & & & $\checkmark$ \\
\hline
\end{tabular}

However, in the literature no works have been identified addressing linear programming optimization models considering uncertain on-hand inventory, which is important to note because the probability that a finished product is completed is equal to $I A^{n}$, assuming the finished product consists of $n$ items and that each item presents the same inventory accuracy (IA). For example, for the case in which a product consists of 10 items and each item has an 
inventory accuracy of $99 \%$, the probability that the product can be completed is $0,99^{10}=0,904$ $=90,4 \%$.

Based on the abovementioned, to the best of our knowledge, proposals for linear programming optimization models have not yet been made considering uncertain available capacity, on-hand inventory and lead times, and assuming lead times dependent on lot sizes for a closed-loop MRP system. For this reason, Section 2 proposes a mathematical model for a deterministic closed-loop MRP model that will serve as the basis for formulating a fuzzy MRP model. Section 3 introduces the MRP model considering fuzzy coefficients for lead times, required capacity, and on-hand inventory. Section 4 presents the results of the implementation of the fuzzy model in a company dedicated to the manufacture of electrical transformers, and Section 5 shows the main conclusions of this study.

\section{APPROACH TO A CLOSED-LOOP MRP MODEL}

The proposed closed-loop MRP model is applicable for manufacturing environments considering capacity constraints, variable demands over time for each item and finished products, allowing inventory accumulation for succeeding periods and considering initial inventory for each item. Likewise, the model considers production and purchase lead times for each item. The model aims to reduce inventory holding costs, setup and extra capacity cost within a production plan for the short and medium-term. Some assumptions of the initial model include the existence of a finite planning horizon, deterministic external demand for each item, and capacity constraints based on the percentage of the use of resources, where the maximum capacity of a resource takes the value of 1 . Thus, it is assumed that the production quantity of each item exceeds the established minimum lot size, and it is assumed that setup and assembly times for the production of each item represent a percentage of the maximum capacity of a resource. Likewise, it is assumed that the variation in the purchase price of raw materials is unrelated to production decisions, therefore the costs of raw materials are excluded. Other assumptions of the proposed model include a multi-level production system where subsets of components are assembled independently, a multi-period planning horizon comprising a set of consecutive and integer time periods of equal length, the inventory of each item represents the volume present at the end of a given period, and the lead time of an item is the number of consecutive and integer periods required for their finalization [5, 18, 29]. The following notation and definition for the indices, parameters, and variables of the model is proposed:

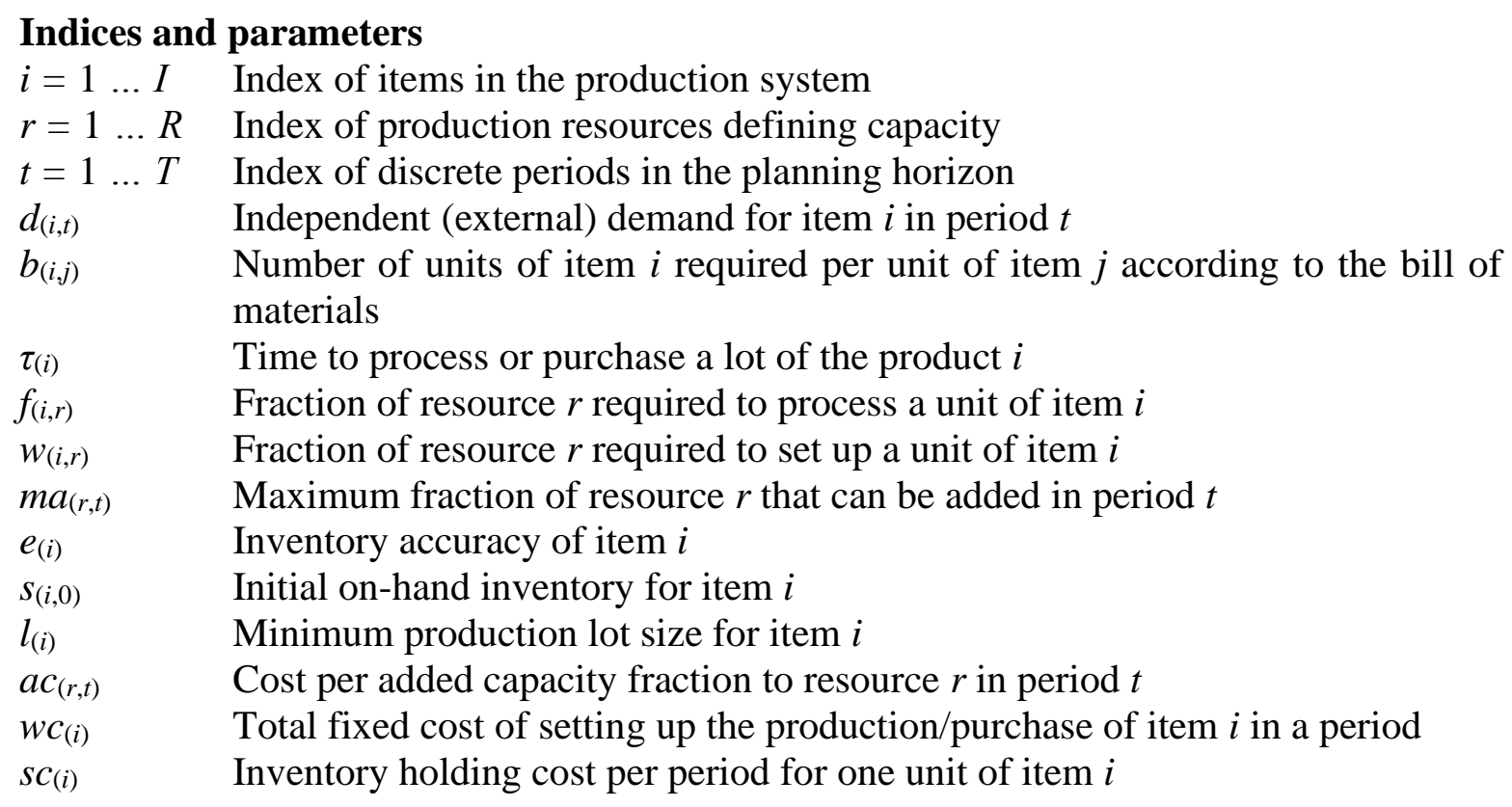




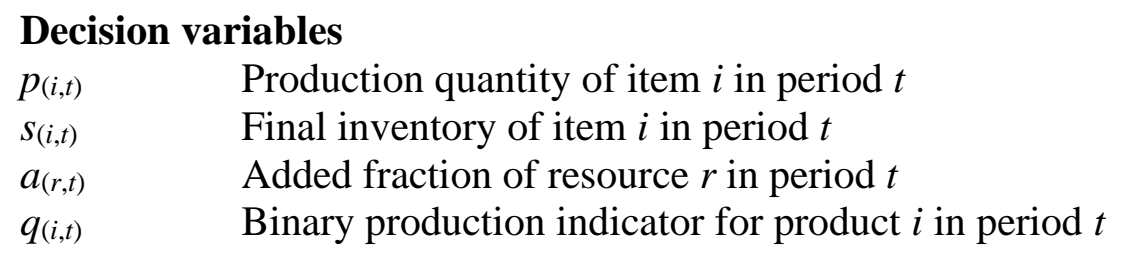

The variable $p_{(i, t)}$ includes the production or purchase quantities of item $i$ in the product structure given by the bill of materials, and the response time $\tau_{(i)}$ represents the production or purchase lead time for each item. On the other hand, the inventory accuracy parameter $e_{(i)}$ represents the inventory accuracy for item $i$, which is expressed as the division between the physical and theoretical inventory of item $i$, and can generate different values for each item due to the characteristics of the components of a given product like turnover ratio, storage system, unit value, item size, among others.

$$
\begin{aligned}
\operatorname{Min} Z=\sum_{t=1}^{T}\left[\sum_{r=1}^{R} a_{(r, t)} a c_{(r, t)}+\sum_{i=1}^{I}\left(q_{(i, t)} w c_{(i)}+e_{(i)} S_{(i, t)} s c_{(i, t)}\right)\right] & \forall i, r, t \\
\sum_{i=1}^{I}\left(p_{(i, t)} f_{(i, r)}+q_{(i, t)} w_{(i, r)}\right) \leq 1+a_{(r, t)} & \forall r, t \\
\sum_{j=1}^{I}\left(p_{(i, t)} b_{(i, j)}\right)+d_{(i, t)}+e_{(i)} s_{(i, t)}=e_{(i)} S_{(i, t-1)}+p_{\left(i, t-\tau_{(i)}\right)} & \forall i, t \\
a_{(r, t)} \leq m a_{(r, t)} & \forall r, t \\
p_{(i, t)} \geq q_{(i, t)} l_{(i)} & \forall i, t \\
q_{(i, t)} \in\{0,1\}, p_{(i, t)} \geq 0, s_{(i, t)} \geq 0, a_{(r, t)} \geq 0 & \forall i, r, t
\end{aligned}
$$

The objective function in Eq. (1) minimizes inventory holding costs, production setup costs, and extra capacity costs in a time horizon $T$. Constraints in Eq. (2) guarantee that the capacity of resource $r$ consumed by setting up and manufacturing item $i$ in a period $t$ will not exceed the maximum capacity and the additional capacity allowed for this resource. Eq. (3) ensures the inventory balance, where the sum of the dependent demand, the independent demand and the ending inventory of item $i$ are equal to the initial inventory and the ordered quantities of item $i$ for period $t$. Eq.(4) restricts the maximum additional capacity of a resource in a period, which is typically generated by limitations in the process related to technological capacity, availability of additional resources and subcontracting, labour legislation, business policies, among others. Constraints (5) establish the minimum production or purchase lot size for an item $i$, responding to the requirements of the manufacturing processes and purchasing policies. Constraints (6) are the domain and non-negativity restrictions on the decision variables.

\section{FUZZY MODEL FOR MATERIAL REQUIREMENTS PLANNING}

The proposed closed-loop MRP model considers uncertainty in the parameters $\tau_{(i)}, f_{(i, r)}$ and $e_{(i)}$, that is, the production or purchase times, the capacity required by each unit of an item in a resource and the inventory accuracy of each item. Therefore, fuzzy coefficients are used in the constraints of the model, and it presents an asymmetric form to measure performance according to different degrees of satisfaction $(\lambda)$ of the decision-maker $[5,16,18,21]$. Likewise, $\lambda$ is used as a coefficient of compensation between efficiency and equity. Three other elements appear in the proposed model allowing to express uncertainty in the selected parameters, being $h_{(i)}$ the maximum slack for the production or purchase time of item $i, g_{(i, r)}$ the maximum tolerance of capacity considered for the manufacture of item $i$ in resource $r$ and $n_{(i)}$ the tolerance for the inventory accuracy of item $i$. Consequently, the production or purchase time of item $i$ can be expressed in intervals $\left[\tau_{(i)}, \tau_{(i)}+h_{(i)}\right]$; the fraction of resource $r$ used to process item $i$ is expressed in intervals $\left[f_{(i, r)}, f_{(i, r)}+g_{(i, r)}\right]$, and the inventory accuracy of item $i$ is expressed as symmetric triangular fuzzy number $\left(e_{(i)}-n_{(i)}, e_{(i)}, e_{(i)}+n_{(i)}\right)$. Based on the definition of the fuzzy coefficients 
of the MRP model, a fuzzy model is proposed, in which both the objective function and the constraints present uncertain parameters. According to [16], the resource capacity constraints can be expressed in an equivalent form as shown in Eq. (7), the inventory balance constraints can be expressed in an equivalent form as shown in Eq. (8) and Eq. (9).

$$
\begin{array}{cc}
\sum_{i=1}^{I}\left[p_{(i, t)}\left(f_{(i, r)}+(1-\lambda) g_{(i, r)}\right)+q_{(i, t)} w_{(i r)}\right] \leq 1+a_{(r, t)} \quad \forall i, r, t & \\
p_{\left(i, t-\left(\tau_{(i)}+(1-\lambda) h_{(i)}\right)\right)}+\left[\left(e_{(i)}+n_{(i)}(1-\lambda)\right)\left(s_{(i, t-1)}-s_{(i, t)}\right)\right]-\sum_{j=1}^{I}\left(p_{(i, t)} b_{(i, j)}\right) \leq d_{(i, t)} & \forall i, t \\
p_{\left(i, t-\left(\tau_{(i)}+(1-\lambda) h_{(i)}\right)\right)}+\left[\left(e_{(i)}-n_{(i)}(1-\lambda)\right)\left(s_{(i, t-1)}-s_{(i, t)}\right)\right]-\sum_{j=1}^{I}\left(p_{(i, t)} b_{(i, j)}\right) \geq d_{(i, t)} & \forall i, t
\end{array}
$$

Additionally, it is necessary to create the auxiliary variable $\operatorname{sreal}_{(i, t)}$, which represents the final inventory resulting from multiplying the final inventory of an item in a period by its accuracy value. Therefore, Eqs. (10) and (11) are added to the equivalent model, and also sreal $_{(i, t)}$ is added to the objective function.

$$
\begin{array}{ll}
{\left[e_{(i)}+n_{(i)}(1-\lambda)\right] s_{(i, t)} \leq \operatorname{sreal}_{(i, t)}} & \forall i, t \\
{\left[e_{(i)}-n_{(i)}(1-\lambda)\right] s_{(i, t)} \geq \operatorname{sreal}_{(i, t)}} & \forall i, t
\end{array}
$$

It should be noted that in the equations where the parameter $\lambda$ is included, as long as the value of the parameter approaches 1 , the constraints of the model are satisfied to a greater degree, while the parameter takes values close to 0 , the constraints of the model are satisfied to a lower degree. Once the conversion of inventory balance and resource capacity constraints are applied, the auxiliary variable is created to include uncertainty in the proposed MRP model, and the degree of satisfaction of the decision-maker $(\lambda)$ is included, the equivalent fuzzy mathematical model conformed by Eqs. (1), (4-6), and (7-11).

To configure the fuzzy model, a degree of satisfaction $(\lambda)$ must be determined by the decision-maker to influence the optimal solution of the production plan, which will be expressed as a crisp. Likewise, when the level of satisfaction level $(\lambda)$ takes values of 1 in the proposed fuzzy model, the fuzzy model is equivalent to the deterministic model. On the other hand, to verify the fuzzy model, we used information from a production plan of a company dedicated to the manufacture of electrical transformers. This information is related to the demand of the finished product in each period, bill of materials, use of work centres in the production system, production/purchase lead times, minimum lot sizes per item, initial inventory of each item, inventory accuracy, inventory holding costs, production setup costs and purchasing costs, maximum tolerance in inventory accuracy, production/purchase times, and capacity consumed by each item, among others. Therefore, the time horizon in the production plan is equivalent to a month, detailed per day, obtaining 30 periods in a production plan. Six work centres (resources) are considered for the manufacture of the finished product, made up of 73 different items, as shown in Fig. 1. The dataset for input data is fully presented at [31], describing the values of each parameter of the MRP model.

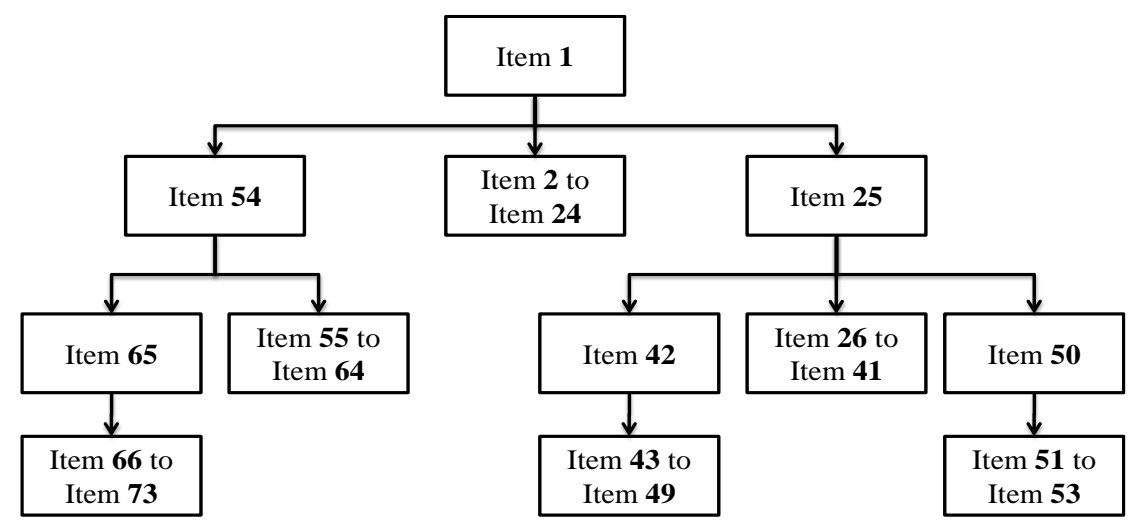

Figure 1: Bill of materials of the selected product. 
This study considers the service level, inventory level, total cost of the production plan, and the computational efficiency to measure the performance of the proposed MRP models. These performance measures evaluate key aspects of the models like the demand fulfilment, investment in finished product inventory, total investment for the production plan, and the computing time to obtain results. The information of the electricity sector company provides both the deterministic model and the fuzzy model, and the proposed models are tested with the GAMS (General Algebraic Modelling System) software package, which is a modelling language as well as a program to solve problems of optimization, offering modelling modules and incorporating different nonlinear, linear and mixed-integer programming solvers. In this case, CPLEX represents the solver selected to solve the MRP models that are considered as mixed integer programming (MIP) problems.

\section{RESULTS AND DISCUSSION}

The proposed fuzzy MRP model considering uncertain manufacturing capacity, in inventory availability, and in lead times is solved in GAMS, thus obtaining different results according to the degree of satisfaction in the constraints preferred by the decision-maker $(\lambda)$. For practical purposes, as described in Table II, the experiments were performed assigning values between 0 and 1 for $\lambda$. The values obtained with $\lambda=1$ correspond to the results produced by the deterministic model, as this is the model obtaining the maximum degree of satisfaction for the constraints. The values obtained for the decision variables in each scenario $(\lambda)$ are shown in [31], detailing the values of $p_{(i, t)}, s_{(i, t)}, a_{(r, t)}, q_{(i, t)}$ for all items $i$, resources $r$, and periods $t$.

To obtain an evaluation of the computational efficiency in the fuzzy model tests, the execution time of the model, the number of iterations, the completion time for the execution of the model and the use of resources were rated on a scale from 0 to 10, assigning 10 to the test with the best performance in each measure, 9 to the test with the second-best performance, and so on until assigning 0 to the worst test. Therefore, the scores rated on a scale from 0 to 10 are computed for each $\lambda$ value, obtaining the computational efficiency value. Consequently, from Table II, the model with $\lambda=0,4$ provides the best computational efficiency.

Table II: Results for the fuzzy MRP model.

\begin{tabular}{|c|c|c|c|c|}
\hline $\boldsymbol{\lambda}$ & $\begin{array}{c}\text { Total cost } \\
\text { (USD) }\end{array}$ & $\begin{array}{c}\text { Total } \\
\text { inventory }\end{array}$ & $\begin{array}{c}\text { Service } \\
\text { level }\end{array}$ & $\begin{array}{c}\text { Computational } \\
\text { efficiency }\end{array}$ \\
\hline 0,0 & $\$ 36.384$ & 3.579 & 0,97 & 18 \\
\hline 0,1 & $\$ 37.278$ & 3.571 & 0,97 & 31 \\
\hline 0,2 & $\$ 38.175$ & 3.562 & 0,98 & 24 \\
\hline 0,3 & $\$ 39.078$ & 3.553 & 0,98 & 26 \\
\hline 0,4 & $\$ 39.979$ & 3.544 & 0,99 & 32 \\
\hline 0,5 & $\$ 41.152$ & 3.718 & 0,99 & 22 \\
\hline 0,6 & $\$ 42.070$ & 3.711 & 1,00 & 29 \\
\hline 0,7 & $\$ 42.991$ & 3.703 & 1,00 & 2 \\
\hline 0,8 & $\$ 43.911$ & 3.695 & 1,00 & 16 \\
\hline 0,9 & $\$ 44.843$ & 3.688 & 1,00 & 18 \\
\hline 1,0 & $\$ 40.719$ & 7.089 & 1,00 & 2 \\
\hline
\end{tabular}

Based on the results of the fuzzy MRP model, Fig. 2 establishes that the total cost of the production plan decreases as the degree of satisfaction $\lambda$ decreases in the inventory balance constraints, where the lead times and inventory accuracy are involved, and as $\lambda$ decreases in the capacity constraints, where the required capacity to manufacture a unit of an item is involved. 
This is explained by the fact that $\lambda$ values close to 0 allow each unit of each item to consume a greater fraction of the resources, allow more or fewer units of on-hand inventory and allow lead times to be longer than usual. All this represents greater flexibility within the production planning parameters that allow considering a broader set of solutions impacting the extra capacity costs, inventory holding, and ordering costs, which constitute the total cost of the production plan. This is proved by measuring the differential between the lowest cost solution $(\lambda=0)$ and the highest cost solution $(\lambda=0,9)$, which represents $\$ 8.459$.
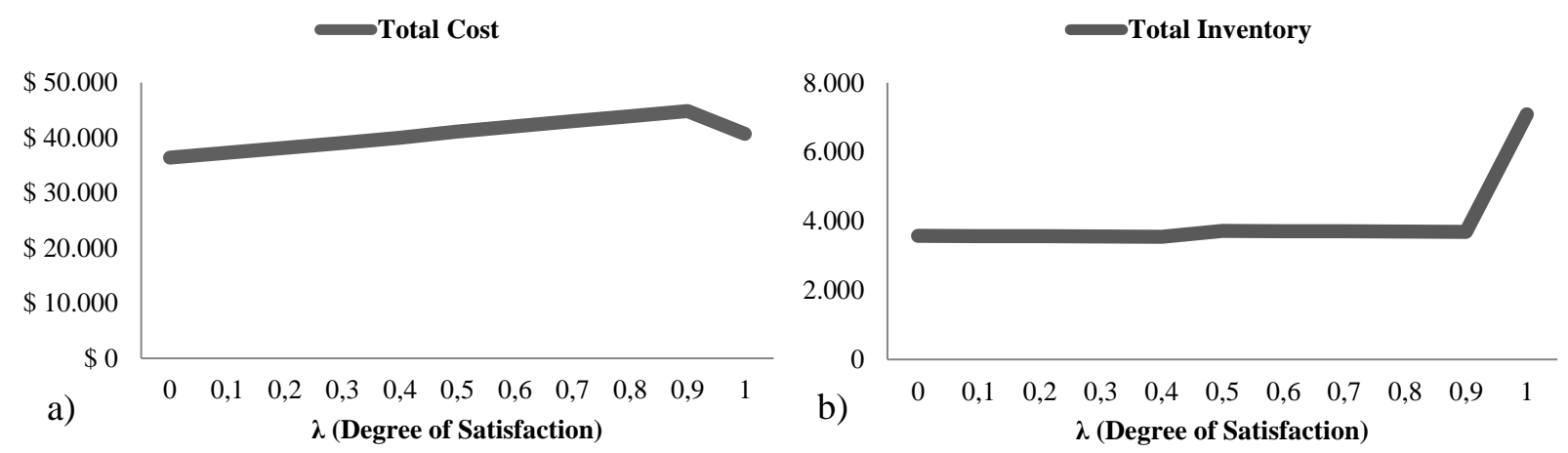

Figure 2: a) Total costs and b) total inventory from the fuzzy MRP model.

When comparing the total costs of the fuzzy model $(\lambda \neq 0)$ with those obtained by the deterministic model $(\lambda=1)$, it is observed that if $\lambda \leq 0,4$ the fuzzy model presents lower total costs, therefore the fuzzy model performs better when the degree of satisfaction of the constraints is limited, that is, when greater flexibility is allowed in the parameters. Unlike, when $\lambda$ takes high values, it causes the total costs to exceed the costs produced by the deterministic model. Likewise, Fig. 2 shows as $\lambda$ decreases, the accumulated sum of inventory held throughout the planning horizon decreases, presenting a significant change when moving from the deterministic model to the fuzzy model. This relationship between $\lambda$ and the total inventory in the planning horizon contributes to the reduction of total costs as $\lambda$ decreases.

Fig. 3 illustrates that as $\lambda$ decreases, the level of service decreases. This information is significant for the decision-maker, who must consider for this model that obtaining lower total costs and less total inventory implies offering a lower service level. Likewise, as $\lambda$ presents values close to zero, the computational efficiency tends to increase, which is explained by the increased flexibility of the model, providing more alternatives to the mathematical programming software to find an optimal solution.
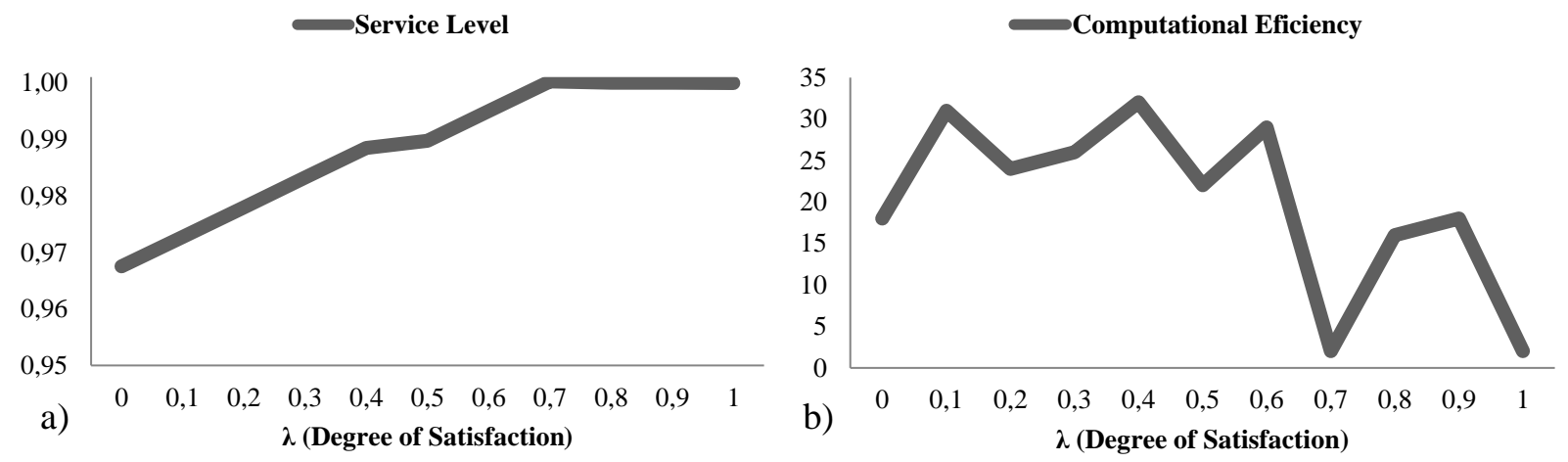

Figure 3: a) Service level and b) computational efficiency from the fuzzy MRP model.

Moreover, Fig. 4 presents the response surfaces of the fuzzy model, showing that as the inventory level increases, the total costs increase, except when the model becomes deterministic due to the fact that the inventory level increases drastically and the total cost is reduced with 
respect to fuzzy models with $\lambda$ values close to 1 . The response surface also indicates that as $\lambda$ increases, the service level and the total inventory increase, reaching service levels of $100 \%$ and stabilizing the inventory level for $\lambda=0,6 ; 0,7 ; 0,8 ; 0,9$. Likewise, when the MRP model becomes deterministic $(\lambda=1)$, achieving a $100 \%$ service level requires inventory levels from approximately double that required in fuzzy models.
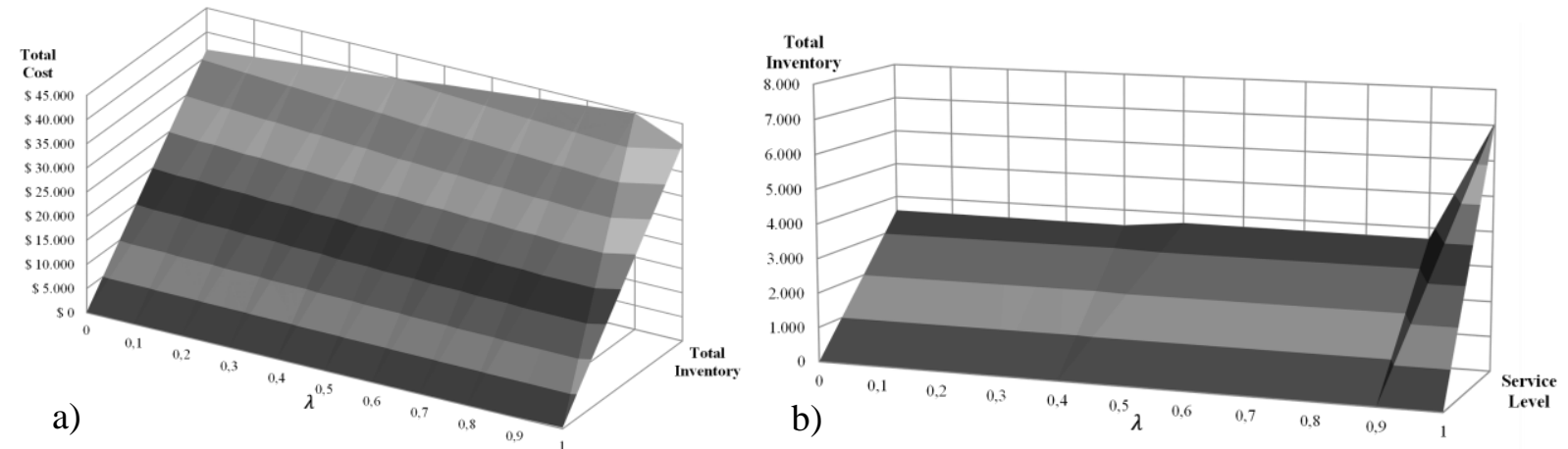

Figure 4: Response surfaces of the MRP model: a) Total cost, $\lambda$, total inventory; b) Total inventory, $\lambda$, service level.

Since multiple performance measures are used to measure the overall efficiency of the fuzzy MRP model, the criteria weighting method is applied to support the rating for each $\lambda$. Table III shows the weights assigned to the four criteria of the MRP models. Then, the values of each performance measure or criterion (total cost, total inventory, service level, computational efficiency) receive a score from 0 to 10 , assigning 0 to the worst value and 10 to the best value of each criterion, and a weighted average is calculated to obtain the overall efficiency for each MRP model $(\lambda)$, as shown in Fig. 5.

Table III: Weighting for the evaluation criteria.

\begin{tabular}{|c|c|c|c|}
\hline Total cost & $\begin{array}{c}\text { Total } \\
\text { inventory }\end{array}$ & $\begin{array}{c}\text { Service } \\
\text { level }\end{array}$ & $\begin{array}{c}\text { Computational } \\
\text { efficiency }\end{array}$ \\
\hline $70 \%$ & $15 \%$ & $10 \%$ & $5 \%$ \\
\hline
\end{tabular}

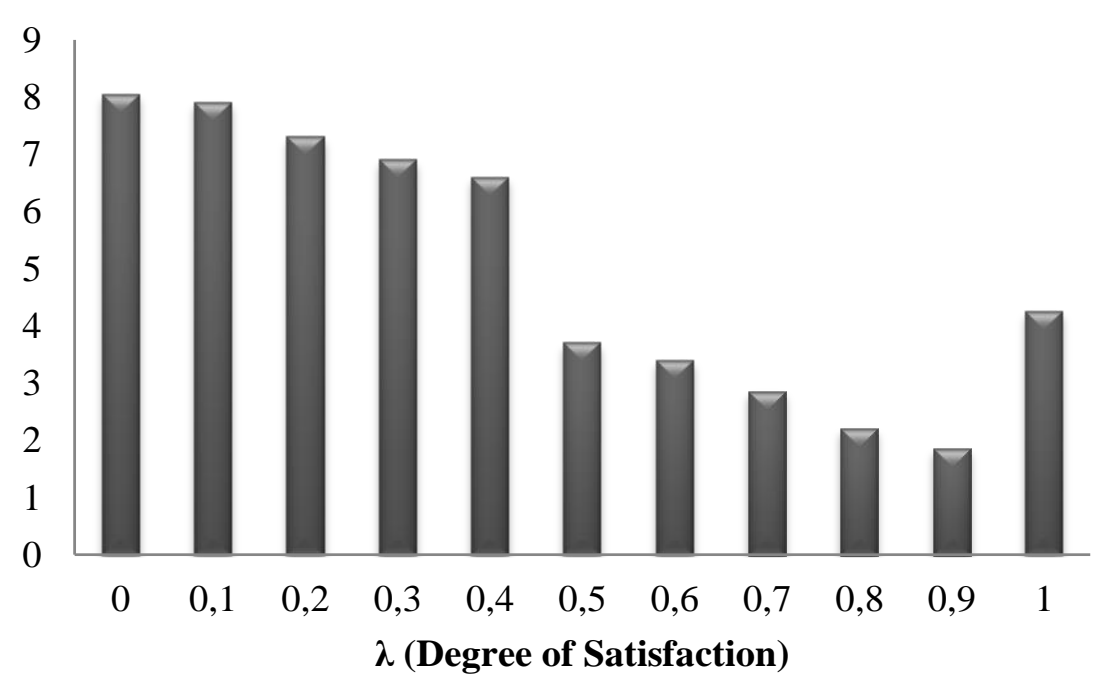

Figure 5: Overall efficiency for the MRP models.

Based on Fig. 5, the best performing models correspond to low degrees of satisfaction for the constraints $(\lambda=0,0 ; 0,1 ; 0,2 ; 0,3 ; 0,4)$, when greater flexibility is allowed in the uncertain parameters. These models provide better performance with respect to the deterministic model 
$(\lambda=1)$, concluding that the fuzzy MRP model leads to more satisfactory results than the deterministic model when greater flexibility is involved in lead times, production capacity and inventory levels.

\section{CONCLUSIONS}

The application of fuzzy logic in closed-loop MRP systems with capacity restrictions represents a valuable option for managing uncertainty, since it facilitates involving the knowledge of experts, especially in the definition of ranges of values for the possibility of the parameters for the proposed optimization model. Involving uncertain parameters like lead times, production capacity and inventory levels, modifies the behaviour of a closed-loop MRP system, providing better results compared to a deterministic model in criteria such as total costs, total inventory, service level and computational efficiency. Likewise, the fuzzy parameters can be adjusted by the decision-maker in charge of production planning, facilitating that membership functions involve historical and subjective information of the production process, and selecting the degree of satisfaction for the constraints of the fuzzy model.

The use of modelling and mathematical programming software, like GAMS, facilitates the operation of fuzzy optimization models since it allows linking with other commonly used software like MS Excel. In this way, the proposed models involving uncertainty can be adopted on a daily basis in real environments, considering the criteria of experts who determine the ranges and fuzzy numbers to describe a parameter. For the electricity sector company addressed in this study, the fuzzy model presented better results with respect to the total cost, total inventory, service level, and computational efficiency when greater flexibility is allowed in fuzzy parameters like on-hand inventory. Therefore, considering uncertainty in the on-hand inventory allows us to better represent the reality of production systems and achieve satisfactory solutions for multiple objectives in operations management.

Future research should involve uncertainty with fuzzy logic in the external demand for finished products and test the fuzzy model for other types of companies. Likewise, it is suggested to evolve in the approach of the membership functions for the fuzzy parameters and determine the rate of change in the overall performance. Finally, further research would be expected to extend the concepts of uncertainty addressed in this study to Master Production Scheduling (MPS) and scheduling problems, and jointly solve a production plan representing real environments of production systems.

\section{REFERENCES}

[1] Velasco Acosta, A. P.; Mascle, C.; Baptiste, P. (2020). Applicability of demand-driven MRP in a complex manufacturing environment, International Journal of Production Research, Vol. 58, No. 14, 4233-4245, doi:10.1080/00207543.2019.1650978

[2] Öztürk, C.; Örnek, A. M. (2012). A MIP based heuristic for capacitated MRP systems, Computers \& Industrial Engineering, Vol. 63, No. 4, 926-942, doi:10.1016/j.cie.2012.06.005

[3] Wang, H.; Gong, Q.; Wang, S. (2017). Information processing structures and decision making delays in MRP and JIT, International Journal of Production Economics, Vol. 188, 41-49, doi:10.1016/j.ijpe.2017.03.016

[4] Sundharesalingam, P.; Mohanasundari, M.; Vidhyapriya, P. (2019). Application of productivity enhancement tools in RIGS manufacturing industry: ABC and MRP, International Journal of Scientific \& Technology Research, Vol. 8, No. 12, 1900-1905

[5] Díaz-Madroñero, M.; Mula, J.; Jiménez, M.; Peidro, D. (2017). A rolling horizon approach for material requirement planning under fuzzy lead times, International Journal of Production Research, Vol. 55, No. 8, 2197-2211, doi:10.1080/00207543.2016.1223382 
[6] Więcek, D.; Więcek, D.; Dulina, L. (2020). Materials requirement planning with the use of activity based costing, Management Systems in Production Engineering, Vol. 28, No. 1, 3-8, doi:10.2478/mspe-2020-0001

[7] Sutrisno, W.; Airlangga, H. N. P. (2020). Analysis of crude oil inventory using the material requirement planning method, IOP Conference Series: Materials Science and Engineering, Vol. 722, Paper 012059, 7 pages, doi:10.1088/1757-899X/722/1/012059

[8] Hencha, R.; Verma, D. S. (2019). Study of material requirement planning processes \& its analysis and implementation (A case study of automobile industry), International Journal of Scientific \& Technology Research, Vol. 8, No. 8, 648-653

[9] Hasanati, N.; Permatasari, E.; Nurhasanah, N.; Hidayat, S. (2019). Implementation of material requirement planning (MRP) on raw material order planning system for garment industry, IOP Conference Series: Materials Science and Engineering, Vol. 528, Paper 012064, 8 pages, doi:10.1088/1757-899X/528/1/012064

[10] Milne, R. J.; Mahapatra, S.; Wang, C.-T. (2015). Optimizing planned lead times for enhancing performance of MRP systems, International Journal of Production Economics, Vol. 167, 220-231, doi:10.1016/j.ijpe.2015.05.013

[11] Du, T. C.-T.; Wolfe, P. M. (2000). Building an active material requirements planning system, International Journal of Production Research, Vol. 38, No. 2, 241-252, doi:10.1080/ 002075400189383

[12] Shofa, M. J.; Moeis, A. O.; Restiana, N. (2018). Effective production planning for purchased part under long lead time and uncertain demand: MRP vs demand-driven MRP, IOP Conference Series: Materials Science and Engineering, Vol. 337, Paper 012055, 7 pages, doi:10.1088/1757$\underline{\text { 899X/337/1/012055 }}$

[13] Kortabarria, A.; Apaolaza, U.; Lizarralde, A. (2019). Demand driven MRP - Nuevo método para la gestión de la cadena de suministro: un estudio de caso, Direccion y Organizacion, Vol. 67, 2229, doi:10.37610/dyo.v0i67.540

[14] Hong, P.; Leffakis, Z. M. (2017). Managing demand variability and operational effectiveness: case of lean improvement programmes and MRP planning integration, Production Planning \& Control, Vol. 28, No. 13, 1066-1080, doi:10.1080/09537287.2017.1329956

[15] Ho, C.-J. (1989). Evaluating the impact of operating environments on MRP system nervousness, International Journal of Production Research, Vol. 27, No. 7, 1115-1135, doi:10.1080/ 00207548908942611

[16] Mula, J.; Poler, R.; Garcia-Sabater, J. P. (2007). Material requirement planning with fuzzy constraints and fuzzy coefficients, Fuzzy Sets and Systems, Vol. 158, No. 7, 783-793, doi:10.1016/j.fss.2006.11.003

[17] Mula, J.; Poler, R.; Garcia-Sabater, J. P. (2008). Capacity and material requirement planning modelling by comparing deterministic and fuzzy models, International Journal of Production Research, Vol. 46, No. 20, 5589-5606, doi:10.1080/00207540701413912

[18] Díaz-Madroñero, M.; Mula, J.; Jiménez, M. (2014). Fuzzy goal programming for material requirements planning under uncertainty and integrity conditions, International Journal of Production Research, Vol. 52, No. 23, 6971-6988, doi:10.1080/00207543.2014.920115

[19] Wang, J. F.; Fei, Z. C.; Chang, Q.; Fu, Y.; Li, S. Q. (2019). Energy-saving operation of multistage stochastic manufacturing systems based on fuzzy logic, International Journal of Simulation Modelling, Vol. 18, No. 1, 138-149, doi:10.2507/IJSIMM18(1)CO1

[20] Uzun Araz, O.; Eski, O.; Araz, C. (2019). A reactive scheduling approach based on fuzzy inference for hybrid flowshop systems, International Journal of Simulation Modelling, Vol. 18, No. 1, 5-18, doi:10.2507/IJSIMM18(1)448

[21] Mula, J.; Poler, R.; Garcia, J. P. (2006). MRP with flexible constraints: A fuzzy mathematical programming approach, Fuzzy Sets and Systems, Vol. 157, No. 1, 74-97, doi:10.1016/ j.fss.2005.05.045

[22] Shi, D. L.; Zhang, B. B.; Li, Y. (2020). A multi-objective flexible job-shop scheduling model based on fuzzy theory and immune genetic algorithm, International Journal of Simulation Modelling, Vol. 19, No. 1, 123-133, doi:10.2507/IJSIMM19-1-CO1 
[23] Dolgui, A.; Louly, A. O.; Prodhon, C. (2005). A survey on supply planning under uncertainties in MRP environments, IFAC Proceedings Volumes, Vol. 38, No. 1, 1-12, doi:10.3182/20050703-6CZ-1902.01426

[24] Noori, S.; Feylizadeh, M. R.; Bagherpour, M.; Zorriassatine, F.; Parkin, R. M. (2008). Optimization of material requirement planning by fuzzy multi-objective linear programming, Proceedings of the Institution of Mechanical Engineers, Part B: Journal of Engineering Manufacture, Vol. 222, No. 7, 887-900, doi:10.1243/09544054JEM1014

[25] Tavakoli-Moghaddam, R.; Bagherpour, M.; Noora, A. A.; Sassani, F. (2007). Application of fuzzy lead time to a material requirement planning system, Proceedings of the $8^{\text {th }}$ WSEAS International Conference on Fuzzy Systems, 208-213

[26] Li, T.; Lin, P.; Sun, G.-J.; Liu, H.-H. (2009). Application of fuzzy programming with recourse in material requirement planning problem, Proceedings of the 2009 International Conference on Measuring Technology and Mechatronics Automation, 546-549, doi:10.1109/ICMTMA.2009.568

[27] Serna, M. D. A.; Serna, C. A.; Ortega, G. P. (2010). Parametric linear programming for a materials requirement planning problem solution with uncertainty, Ingenieria e Investigacion, Vol. 30, No. 3, 96-105

[28] Guillaume, R.; Thierry, C.; Grabot, B. (2011). MRP with imprecise demand and uncertain lead time, Proceedings of the $7^{\text {th }}$ Conference of the European Society for Fuzzy Logic and Technology, 673-679, doi:10.2991/eusflat.2011.131

[29] Diaz-Madroñero, M.; Mula, J.; Jiménez, M. (2015). Material requirement planning under fuzzy lead times, IFAC-PapersOnLine, Vol. 28, No. 3, 242-247, doi:10.1016/j.ifacol.2015.06.088

[30] Ammar, O. B.; Guillaume, R.; Thierry, C. (2016). MRP parameter evaluation under fuzzy lead times, IFAC-PapersOnLine, Vol. 49, No. 12, 1110-1115, doi:10.1016/j.ifacol.2016.07.644

[31] Cano, J. A. Data World: Dataset Fuzzy MRP System, from https://data.world/joseale84/fuzzy-mrpsystem, accessed on 13-11-2020 